GLOBAL JOURNAL OF PURE AND APPLIED SCIENCES VOL. 24, 2018: 75-80

COPYRIGHTC BACHUDO SCIENCE CO. LTD PRINTED IN NIGERIA ISSN 1118-0579

www.globaljournalseries.com, Email: info@globaljournalseries.com

\title{
LESSONS FROM INTEGRATION OF MASS NUTRITION SCREENING DURING COMBINED BOPV/IPV CAMPAIGN IN ARMED CONFLICT SETTINGS, BORNO STATE, NIGERIA
}

\begin{abstract}
DICK CHAMLA, OLUSOLA OLADEJI, SULE MELE, HELNI MSHELIA, IFEANYI MADUANUSI, AMINU USMAN, ONOME DIBOSA-OSADOLOR, ABIMBOLA AMAN OLONIYO, ELFRIEDE KORMAWA, JOHN AGBOR, ARJAN DE WAGT, BAMIDELE OMOTOLA, ABDULKADIR MUSSE AND NAQIBULLAH SAFI
\end{abstract}

(Received 26 February 2018; Revision Accepted 18 April 2018)

\begin{abstract}
Background: The Boko Haram insurgency has led to severe humanitarian crisis with high levels of malnutrition and polio outbreak in Borno state, Nigeria. In response, outbreak campaigns were conducted that provided an opportunity to integrate nutrition screening during the combined bivalent oral and inactivated polio vaccination (bOPV/IPV) campaign.

Methods: This was a cross-sectional study that measured nutrition status of children using a mid-upper arm circumference (MUAC) measurement tape during bOPV/IPV campaign in 4 of the 24 local government areas (LGAs). Data were collected using tally sheets and mobile ODK Collector and bivariate analysis using logistic regression done.

Results: Over 1.66 million and 1.47 million children received bOPV and IPV vaccines respectively in 24 LGAs. The coverage of bOPV and IPV in integrated and non-integrated LGAs were above $90 \%$ with no statistical difference (OR:0.85; 95\%Cl: 0.55-1.29; p=0.42). Only 48.5\% (351795/725509) of targeted children were screened for malnutrition, of those $3.7 \%(13050 / 351795)$ had severe acute malnutrition (SAM). Less than $47.5 \%$ of children with SAM were successfully referred and enrolled in the treatment facilities.

Conclusion: Coverage of bOPV and IPV were similar in both integrated and non-integrated LGAs indicating that integrating nutrition screening in polio campaigns is feasible with minimal negative effects. As children with SAM have lower serological protection against polio, provides a strong rationale for inclusion of nutrition interventions in global polio eradication efforts. There are critical lessons that were identified including joint planning, well-defined optimal partnership including military collaborations, and a need for joint monitoring.
\end{abstract}

WORD COUNT: 3650

KEYWORDS: Integration; nutrition; polio; MUAC, campaign.

\section{INTRODUCTION}

In the outset of Sustainable Development Goals (SDGs), a Polio-free Africa was a realistic scenario, however the occurrence of four cases of wild poliovirus (WPV) in northern state of Borno, has retrogressed Nigeria in the global map of endemic countries (Roberts 2016). This new polio outbreak is further amplified by recent reports of a child with vaccine-derived polio virus (cVDPV2) in the Monguno local government area (LGA) of Borno state (Etsano et al 2016). As LGAs continue to be liberated from the Boko Haram insurgency, more cases of Polio are likely to be identified, underscoring the importance of successive rounds of polio vaccination campaigns.

The impact of conflicts on health infrastructure including immunization services is widely documented (Adil et al 2013), and Borno state is not an exception. There is a raft of literature on the violence against polio workers and disruption of immunization campaigns in various conflicts including by Boko Haram armed group (Adil et al 2013, Bigna 2016). The Boko Haram

Dick Chamla, Emergency Response Team, UNICEF, New York.

Olusola Oladeji, Health Section, UNICEF, South Sudan.

Sule Mele, Borno State Primary Health Care Development Agency, Maiduguri.

Helni Mshelia, Borno State Primary Health Care Development Agency, Maiduguri.

Ifeanyi Maduanusi, Borno Field Office, UNICEF, Maiduguri, Nigeria.

Aminu Usman, Borno Field Office, UNICEF, Maiduguri, Nigeria.

Onome Dibosa-Osadolor, Health section, UNICEF, Abuja, Nigeria.

Abimbola Aman Oloniyo, Health section, UNICEF, Abuja, Nigeria.

Elfriede Kormawa, Health section, UNICEF, Abuja, Nigeria.

John Agbor, Health section, UNICEF, Abuja, Nigeria.

Arjan De Wagt, Health section, UNICEF, Abuja, Nigeria.

Bamidele Omotola, Health section, UNICEF, Abuja, Nigeria.

Abdulkadir Musse, Emergency Response Team, UNICEF, New York.

Naqibullah Safi, Emergency Response Team, UNICEF, New York. 
insurgency has also resulted in severe food insecurity with high rates of severe acute malnutrition (SAM) well above emergency thresholds (Vahyala and Kabiru 2016). Yet limited access to health services and population displacements means more children with malnutrition continue to be left without appropriate interventions. UNICEF estimates that, 75,000 children will likely die over the next year if the current levels of international support remain the same (Washington post 2016).

In Nigeria, polio campaigns have been conducted annually for decades providing a unique opportunity for integration of nutrition screening aimed at reaching children who could not access health care. In response to the current polio outbreak, five campaign rounds of outbreak response (OBR) using bivalent Oral Polio Vaccines (bOPV) were planned in eighteen states. Inactivated Polio Vaccine (IPV) along with mass nutrition screening were included during the phased second round OBR in Borno State. During the first phase of the second $O B R$, mass nutrition screening was piloted in the LGA of Konduga, and during the second phase, this nutrition screening was extended to three populous LGAs of Maiduguri, Jere and Mafa. As this was the first time for such integration to occur during bOPV/IPV campaign in Nigeria, lessons learned from microplanning stage to actual implementation and data collection will be invaluable for future integrated campaigns and for adapting in other settings.

\section{Boko Haram insurgency in Northern Nigeria}

The Jama'atu Ahlis Sunna Lidda'awati wal-Jihad, commonly known as Boko Haram, is the armed insurgency group that forbids western education. The group founded in 2002, launched its military attacks to create a caliphate in geographical areas that were captured. By the end of 2015, Boko Haram completely controlled over 11 LGAs mostly in northern Borno and have evolved to become a geo-political threat to neighbouring countries of Cameroon, Chad and Niger ( OCHA 2015; Bank 2016).

It is estimated that Boko Haram is responsible for over 20,000 civilian deaths and economic loss of over USD6bn, primarily due to partial or complete damage of infrastructure (Bank 2016). In addition, mass abductions including the infamous kidnapping of 200 school girls from Chibok LGA, and mass displacements of over 2 million people were reported. These have led to severe food insecurity, disproportionately affecting women and children, formation of formal and informal Internally Displaced Persons (IDP) camps, and to the resurgence of polio (OCHA 2015).

\section{METHODS}

The study was cross-sectional, multisite and community based that measured nutrition status of children using a mid-upper arm circumference (MUAC) measurement tape during a combined bOPV/IPV campaign in four (Jere, Konduga, Mafa and Maiduguri metropolitan city) of the 24 LGAs of in September 2016. The eligibility criteria included children attending polio campaign aged less than 60 months of age for bOPV; aged between 6 weeks and 59 months for IPV; and those aged 6-59 months for nutrition screening.
The Nutrition screening was done by measuring MUAC using a color-coded tape and examination of presence of oedema (swelling of feet). Children were classified as having severe malnutrition (SAM) if the MUAC measurement was red $(<11.5 \mathrm{~cm})$. Those with SAM were referred to treatment facilities where they received Ready-to-Use Therapeutic Food (RUTF) as per national and the $\mathrm{WHO}$ guidelines.

The main hypothesis was that inclusion of nutrition screening during the polio campaign could be an effective case finding strategy for children with severe malnutrition by promoting availability and accessibility of services closer to their communities. Similarly, it was assumed that the social mobilization efforts by Volunteer Community Mobilizers (VCM) preceding the campaign could increase awareness and demand of polio and nutrition screening alike. Knowing nutrition status of the children receiving polio vaccination could also be important due to the association between malnutrition and serological response to polio (Yousuf et al 2015).

\section{The campaign design}

The design and implementation of the integrated campaign were based on state microplans developed by the government with the support of international partners. The campaign was implemented in two phases due to the shortage of health workers needed for the administering IPV injections as per national guidelines. There were two separate microplans for the polio and nutrition campaigns. Due to the lack of reliable population figures, the immunization targets were based on the 'highest number immunized' in the first OBR whilst nutrition targets assumed that $80 \%$ of children receiving IPV would be age-eligible for MUAC screening. The integrated campaign was coordinated at the state's Emergency Operations Centre (EOC) chaired by the government with the five major partners of Global Polio Eradication Initiative (GPEI) - UNICEF, WHO, Bill and Melinda Gates Foundation, Rotary International Polio Plus and US CDC.

The integrated campaign was manned by a team of 9 OPV/IPV personnel comprising of two vaccinators, two data collectors, crowd controller, town announcer, pluses distributor and a supervisor, who were joined by a 3-member nutrition team that included a nutrition screener, a data recorder and a nutrition supervisor. In total, there were 3368 teams with 1019 in phase 1 LGA while 2349 were deployed in phase 2 . The nutrition workforce comprised a total of 2704 individuals. The vaccine vials were picked from central cold room in Maiduguri by LGA supervisors using 44L cold boxes (Dometic RCW25). Giostyle vaccine carriers and icepacks were used to distribute a total of $1,851,100$ doses of bivalent oral polio vaccine (bOPV) and 1,890,000 IPV doses. Due to severe insecurity in some areas, armed military escorts for personnel and supplies were needed.

A campaign site where the integrated delivery of polio and nutrition screening was implemented was called a 'health camp'. In each health camp, bOPV followed by an IPV dose, nutrition screening and completed with the distribution of sugar packs (pluses). Nutrition screening was conducted after vaccinations in order to minimize interruptions of OPV/IPV administration. Children with SAM were referred to an 
Outpatient treatment program (OTP) in fixed primary health care $(\mathrm{PHC})$ facilities or to outreach $\mathrm{PHC}$ sites developed for the campaign. Referral of children employed various mechanisms including the use of Volunteer Community Mobilizers (VCMs), self-referral using a 'referral slip' and in some instances workerassisted referrals. In OTP, children were rescreened and those eligible were enrolled in OTP program and given Ready-to-Use Therapeutic Food (RUTF) and educational messages.

\section{Sampling, data collection and analysis}

All children participating in polio campaign were selected and consecutively included in the study until the end of campaign hours (6am to $1 \mathrm{pm}$ ). Data was collected in two phases from $17^{\text {th }}$ to $22^{\text {nd }}$ and $24^{\text {th }}$ to $29^{\text {th }}$ September respectively. Tally sheets and improvised nutrition registers were used separately by polio and nutrition data recorders respectively. Different mechanisms were also used for transferring data from the health camps to central level for analysis. While OPVIIPV data were collated daily at Ward, LGA and State (EOC) levels, nutrition data were sent electronically to the online database and collated at federal level.

The primary outcomes of this campaign were coverage of bOPV and IPV comparing integrated and non-integrated LGAs; nutrition screening; and proportion of children screened who had Severe Acute Malnutrition (SAM). The proportion of SAM cases referred to the treatment sites was also analysed. In addition, qualitative information on the reasons for noncompliance were documented and grouped into recurrent themes. Data from OPV/IPV tally sheets were entered into an excel worksheet (Microsoft, Seattle 2013) for analysis, while nutrition data were entered into Samsung Galaxy Tab4 smartphones using ODK Collector version 1.4.5 app (@Google, California, 2016) then uploaded into an online database for analysis.

\section{RESULTS}

In total, $98 \%(1,660,417 / 1,698,950)$ and $91 \%$ $(1,472,432 / 1,618,354)$ of targeted children were vaccinated with bOPV and IPV respectively. The combined coverage of bOPV and IPV among integrated and non-integrated LGAs were $92.3 \%$ and $92.2 \%$, and $105.1 \%$ and $89.5 \%$ respectively, which was not statistically different (OR: $0.85 ; 95 \% \mathrm{Cl}$ : 0.55-1.29; $\mathrm{p}=0.42$ ). However, the coverage was not uniform across LGAs as shown in figure 1, though most attained the coverage of more than $90 \%$ except Konduga which was the first LGA to pilot integrated delivery. Similarly with the exception of Konduga, there were no major differences in coverage of bOPV and IPV between integrated and non-integrated LGAs respectively.

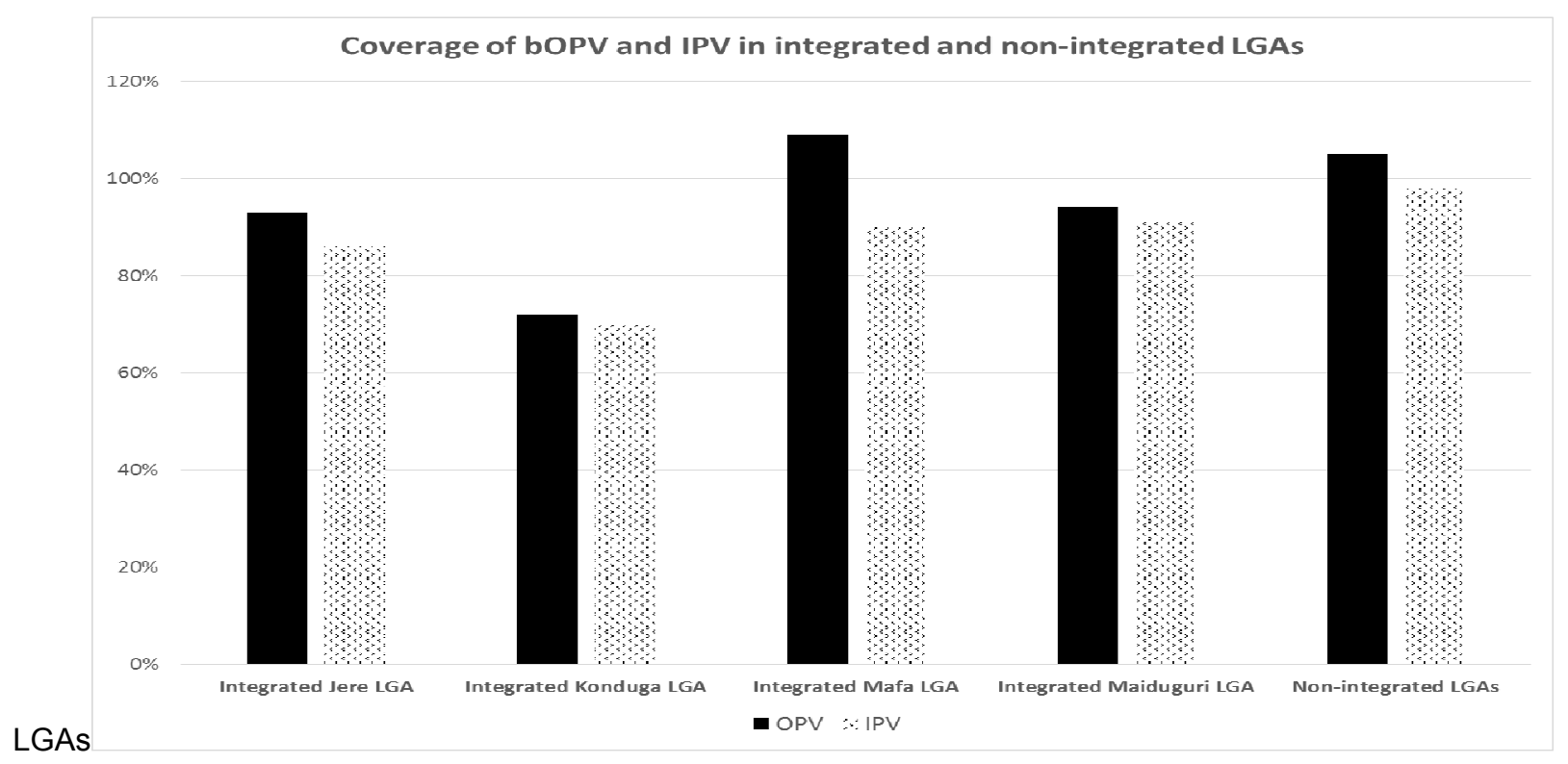

Figure 1: Coverage of bOPV and IPV in integrated and non - integrated

For nutrition, a total of 351,795 children were screened in the four LGAs of Konduga, Maiduguri, Mafa and Jere that integrated nutrition screening into OPV/IPV campaign. This represented $48.5 \%$ (351795/725509) of the intended target. The proportion of children screened that were found to be severely malnourished was $3.7 \%$
(13050/351795). Data on children with SAM admitted for treatment was available for Mafa, Maiduguri and Jere showing admission rate of $47.5 \%$ (5671/11929). This leaky cascade of nutrition screening during the OPV/IPV campaign is shown in figure 2 . 
78 DICK CHAMLA, OLUSOLA OLADEJI, SULE MELE, HELNI MSHELIA, IFEANYI MADUANUSI, AMINU USMAN, ONOME DIBOSA-OSADOLOR, ABIMBOLA AMAN OLONIYO, ELFRIEDE KORMAWA, JOHN AGBOR, ARJAN DE WAGT, BAMIDELE OMOTOLA, ABDULKADIR MUSSE AND NAQIBULLAH SAFI

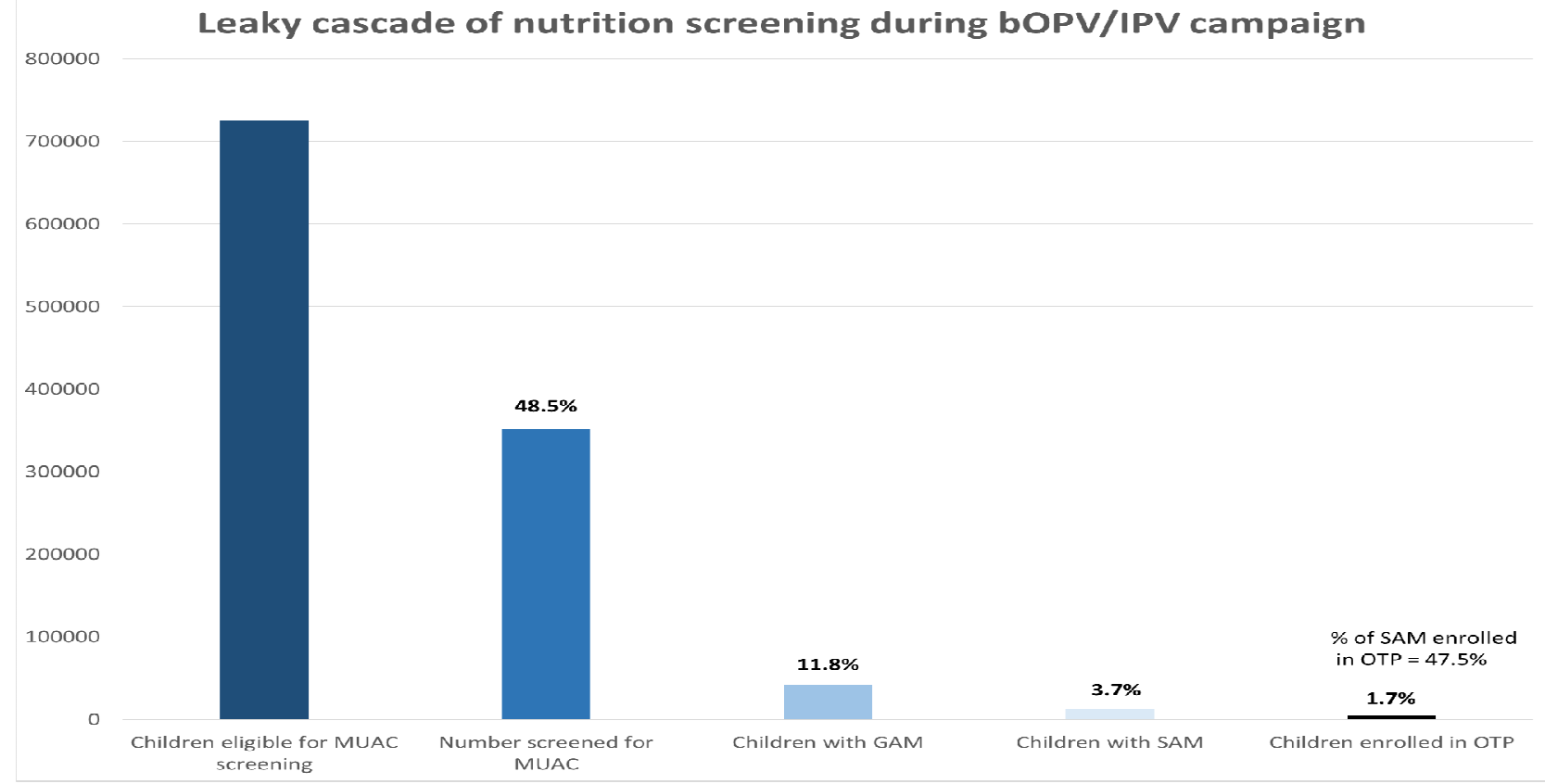

Figure 2: Leaky cascade of nutrition screening during bOPV/IPV campaign

In table 1, of the four integrated LGAs, Konduga had the lowest proportion of children screened, $22.8 \%$ (20383/89378). Konduga and Mafa were LGAs where the largest proportions of children with SAM and GAM were identified. Maiduguri metropolitan city was the LGA that enrolled most children with SAM to the OTP sites $(68.8 \%)$, while Mafa enrolled the fewest (31.6\%).

Table 1: Nutrition screening by Local Government Area

\begin{tabular}{|l|l|l|l|l|l|}
\hline & Target & MUAC screened & \% with SAM & \% with GAM & $\begin{array}{c}\text { of } \\
\text { Enrolled in OTP }\end{array}$ \\
\hline Jere & 222435 & $125932(56.6 \%)$ & $5037(4.0 \%)$ & $15490(12.3 \%)$ & $1758(34.9 \%)$ \\
\hline Konduga & 89378 & $20383(22.8 \%)$ & $1121(5.5 \%)$ & $3098(15.2 \%)$ & No data \\
\hline Mafa & 32827 & $26263(80.0 \%)$ & $2232(8.5 \%)$ & $5253(20.0 \%)$ & $705(31.6 \%)$ \\
\hline Maiduguri & 380869 & $179217(47.1 \%)$ & $4660(2.6 \%)$ & $17742(9.9 \%)$ & $3208(68.8 \%)$ \\
\hline Total & $\mathbf{7 2 5 5 0 9}$ & $\mathbf{3 5 1 7 9 5 ( 4 8 . 5 \% )}$ & $\mathbf{1 3 0 5 0 ( 3 . 7 \% )}$ & $\mathbf{4 1 5 8 3 ( 1 1 . 8 \% )}$ & $\mathbf{5 6 7 1 ( 4 7 . 5 \% )}$ \\
\hline & $\begin{array}{l}\text { SAM= Severe Acute Malnutrition } \\
\text { GAM= Global acute Malnutrition } \\
\text { OTP= Outpatient Treatment Program }\end{array}$ \\
\hline
\end{tabular}

\section{Non-compliance for polio vaccination}

There was a report of a block non-compliance for polio vaccination involving 30 eligible children in Chingowa ward of Magumeri LGA, which was not part of integrated campaign. The most frequent reason given for noncompliance was religious faith. This non-compliance was resolved one day later following the visit and information to the parents from religious and traditional leaders, and heads of the district and village.

\section{DISCUSSION}

Integration has evolved to be one of the service delivery models with the potential to enhance casefinding, efficiencies, and health outcomes(Chamla et al 2015). Yet, understanding and implementing effective models of integrated approaches remain difficult. This initiative provides a unique opportunity to expand the knowledge of integration, in particular key lessons that precluded or facilitated integrated delivery of polio and nutrition services which are traditionally vertical programs.

From the findings, Konduga LGA had the lowest proportion of children that were screened for malnutrition, and the lowest coverage of both, bOPV and IPV compared to other LGAs. This is likely due to the fact that Konduga was the first LGA that first piloted the integrated campaign encountering most challenges. These included mismatch between the number of personnel and health camps, inadequate OTP sites due to closure of fixed sites and limited number of temporary OTP that were functional. Some of the challenges were addressed during the subsequent pilots in Jere, Mafa and Maiduguri LGAs. 
The planning, implementation and results of this integrated polio campaign in armed-conflict settings highlights a few critical issues that are important for future rounds of integrated campaigns. The findings indicate that integrating nutrition screening in mass campaign settings, if well planned and organized, is feasible and acceptable with little or no negative consequences on the uptake of bOPV and IPV as the coverage was mostly above $90 \%$ for both integrated and non-integrated LGAs. Separate microplanning by Polio and Nutrition programs most likely discouraged joint ownership of the integrated campaign and translated into separate teams, supervision, logistics processes, data collection and reporting. Under such circumstances, the model of integration that was implemented during the campaign was actually a colocation of bOPV/IPV provision and nutrition screening within the health camp. This is a similar model of integration that other health programs such as HIV and Tuberculosis (TB) have implemented for decades (WHO 2012) but have failed to adequately institutionalize their integration and co-delivery of services in one encounter (Charles et al 2016). As such, a third program - TB/HIV collaboration with its own structure, emerged in some countries.

Studies have shown that children with severe malnutrition have lower serological protection against polio (Yousuf et al 2015). The combined bOPV/IPV provision has also been shown to boost sero-conversion and confer better immunity to polio among malnourished children (Saleem et al 2015). This highlights the importance of nutrition interventions in polio eradication efforts and provides a strong rationale for this integrated campaign, yet there was no evidence of buy-in from all members of GPEI in the implementation of the integrated campaign. Future implementation of polio/nutrition integrated campaigns should therefore be preceded by robust strategies for building consensus among partners.

Whilst integrating nutrition screening is important, it is a means to an end as the ultimate purpose of screening is to identify severely malnourished children and link them to appropriate treatment programs. Less than half of SAM children were successfully linked to OTP in this initiative most likely due to a number of challenges that could likely be addressed by a joint planning and supervision. Another major factor that affected referral and treatment was closure of fixed OTP sites in the Primary Health Care (PHC) facilities due to most health workers being mobilized for the bOPV/IPV campaign. The closure of these PHC facilities widely affected the provision of other health services underscoring a need for a business continuity plan during mass campaigns in settings where health workers are inadequate.

Massive logistics requirement for bOPV/IPV campaign in conflict-affected Borno state was evident and involved multiple actors including the military infrastructure. Unlike many emergencies, the civilmilitary interface in Borno is complex as most aspects of humanitarian operations require military support. Defining optimal partnership models, including military involvements for effective logistics operations in campaigns during armed conflicts needs further elucidations.
Likewise, unreliable population data had a significant impact of targets which were proposed for both, polio and nutrition screening. Separate data tools and reporting in this integrated campaign undermined the joint ownership of data and accountability. Strict adherence by campaign teams of daily targets based on defunct data, likely led to missed opportunities for reaching additional children with polio vaccination and nutrition screening.

\section{CONCLUSION}

For a successful integrated polio and nutrition campaign in the future, one coordination structure, one micro-plan and one monitoring framework will be critical and likely to facilitate the joint implementation and results. Significant successes have been documented in programs such as HIVIAIDS that adopted a similar joint framework codified as the 'Three Ones' (UNAIDS 2004). Broad consensus among polio partners remains important for determining the model of integration that could maximize outcomes. Using polio structures to optimize nutrition outcomes could be an important aspect of the post-polio framework - a Polio Legacy. A continuum of nutrition care, from screening to treatment, should be a minimum package for integration that could improve child survival.

Broad partnership framework that include a clearlydefined role of the military in polio eradication during armed-conflict settings needs a global discourse as access to insecure settings requires robust military support. In the long term, this framework could guide polio microplanning processes in conflict-affected settings within the auspices of humanitarian principles.

\section{ACKNOWLEDGEMENT}

The authors wish to thank all health workers who participated in the integrated campaign; members of emergency operations centre; Borno primary health care development agency; the world health organization and UNICEF polio and nutrition teams. In particular, special thanks to the support provided by Ms Ranganai Matema (UNICEF Abuja); and Mary Maketo, Engineer Sunday Yinusa Obetule, Mohammad Ibrahim, Austin Tino, Ogu Enemaku, and Gerida Birukila all from UNICEF Borno field office for their immense support during the implementation of the campaign.

\section{Competing interests}

Authors declare no competing interests

\section{Authors' contributions}

$\mathrm{DC}$ and $\mathrm{OO}$ analysed the data, conceived the documentation and drafted and finalized the manuscript. IM, AU, SM, HM and EK coordinated data collection for both polio and nutrition, reviewed the draft, and provided valuable insights of local and historical contexts. OD, AA coordinated vaccine delivery during the campaign, provided information on campaign logistics and reviewed the manuscript. JA, AW and AM provided overall supervision, and reviewed the manuscript. All the authors read and approved the final draft of the manuscript. 
80 DICK CHAMLA, OLUSOLA OLADEJI, SULE MELE, HELNI MSHELIA, IFEANYI MADUANUSI, AMINU USMAN, ONOME DIBOSA-OSADOLOR, ABIMBOLA AMAN OLONIYO, ELFRIEDE KORMAWA, JOHN AGBOR, ARJAN DE WAGT, BAMIDELE OMOTOLA, ABDULKADIR MUSSE AND NAQIBULLAH SAFI

\section{REFERENCES}

Adil, M., Johnstone, P., Furber, A., Siddiqi, K. and Khan, D., 2013. Violence against public health workers during armed conflicts. Lancet, 381(9863):293.

Bank, W., 2016. Post-insurgency Recovery and Peacebuilding Assessment in Northeastern Nigeria. In. Washington: World Bank;

Bigna, J. J., 2016. Polio eradication efforts in regions of geopolitical strife: the Boko Haram threat to efforts in sub-Saharan Africa. Afr Health Sci, 16(2):584-587.

Chamla, D. D., Essajee, S., Young, M., Kellerman, S.,

Lovich, R., Sugandhi, N., Amzel, A and Luo, C., 2015. Integration of HIV in child survival platforms: a novel programmatic pathway towards the 90-9090 targets. J Int AIDS Soc, 18(Suppl 6):20250

Charles, M. K., Lindegren, M. L., Wester, C. W., Blevins, M., Sterling, T. R., Dung, N. T., Dusingize, J. C., AvitEdi, D., Durier, N and Castelnuovo, B. et al., 2016. Implementation of Tuberculosis Intensive Case Finding, Isoniazid Preventive Therapy, and Infection Control ("Three I's") and HIVTuberculosis Service Integration in Lower Income Countries. PLoS One, 11(4):e0153243.

Etsano, A., Damisa, E., Shuaib, F., Nganda, G. W., Enemaku, O., Usman, S., Adeniji, A., Jorba, J., Iber, J and Ohuabunwo, C. et al., 2016. Environmental Isolation of Circulating Vaccine-Derived Poliovirus After Interruption of Wild Poliovirus Transmission Nigeria, MMWR Morb Mortal Wkly Rep 2016, 65(30):770-773.

OCHA: Humanitarian Need Overview. In. Nigeria: OCHA; 2015
Roberts, L., 2016. INFECTIOUS DISEASE. New polio cases in Nigeria spur massive response. Science, 353(6301):738

Saleem, A. F., Mach, O., Quadri, F., Khan, A., Bhatti, Z., Rehman, N. U., Zaidi, S., Weldon, W. C., Oberste, S. M and Salama, M. et al., 2015. Immunogenicity of poliovirus vaccines in chronically malnourished infants: a randomized controlled trial in Pakistan. Vaccine, 33(24):2757-2763.

UNAIDS. 'Three Ones' key principles [http://data.unaids.org/UNA-docs/threeones keyprinciples en.pdf 2004]

Vahyala, T. A., MK, Kabiru, U., 2016. The effects of Boko Haram insurgency on food security status of some selected local government areas in Adamawa State, Nigeria. Sky Journal of Food Science, 5(3):12-18.

Washington potst newspapers. 75,000 children in Nigeria could die from hunger next one year [https://www.washingtonpost.com/news/worldvie ws/wp/2016/10/14/75000-children-in-nigeriacould-die-from-hunger-over-the-next-year/]

WHO, 2012. WHO policy on collaborative TB/HIV activities: guidelines for national programmes and other stakeholders. In. Geneva: World Health Organization;

Yousuf, A., Syed Shah, S. A., Syed Jaffery, I. A., Ahmed, S. A., Khan, M. A., Aslam, M., 2015. Seroprevalence rate of Poliovirus antibodies among the Healthy and Protein Energy Malnutrition children. Pak J Med Sci, 31(2):403407. 